\title{
EI IAPH planifica una segunda edición del MOOC Patrimonio cultural de Andalucía
}

El curso en línea, masivo, gratuito y abierto (MOOC) Patrimonio cultural de Andalucía organiza nueva convocatoria este año 2022. Es una iniciativa del Instituto Andaluz del Patrimonio Histórico (IAPH), en colaboración con el Instituto Andaluz de Administración Pública (IAAP). Este curso va dirigido, por una parte, al personal no especializado en patrimonio cultural dentro de las administraciones públicas, y, por otra, está abierto a toda la ciudadanía interesada en el patrimonio cultural de Andalucía. La primera edición del MOOC se celebró entre el 28 de abril y el 2 de junio de 2021 y se matricularon un total de 1.337 personas.

Carlos Romero Moragas | Área de Formación y Publicaciones, Instituto Andaluz del Patrimonio Histórico

URL de la contribución <http://www.iaph.es/revistaph/index.php/revistaph/article/view/5085>

En 2022 se realizará una nueva convocatoria del MOOC Patrimonio cultural de Andalucía, a celebrar del 11 de mayo al 22 de junio. El curso, integrado dentro de la oferta del Plan Anual de Formación del Instituto Andaluz de Administración Pública (IAAP), es también gratuito y abierto a todas las personas que deseen participar, cuya inscripción se abrirá aproximadamente un mes antes de la fecha de inicio, en el sitio web.

El MOOC Patrimonio cultural de Andalucía es una iniciativa del IAPH, en colaboración con el Instituto Andaluz de Administración Pública (IAAP). Se trata de un curso de introducción al patrimonio cultural que, de manera didáctica, a través de vídeos y textos de apoyo, pretende concienciar sobre el concepto de patrimonio cultural, sus principales tipologías, las acciones que se realizan para su conocimiento y salvaguarda así como los principales agentes implicados. También sobre la importancia de la ciudadanía en su conocimiento y disfrute, desde la perspectiva de la sostenibilidad.

Este curso va dirigido, por una parte, al personal no especializado en patrimonio cultural dentro de las administraciones públicas, y, por otra, está abierto a toda la ciudadanía interesada en el patrimonio cultural de Andalucía: agentes asociativos o docentes con interés en el patrimonio y cualquier persona sensible a su conocimiento y conservación.
La justificación de un curso MOOC sobre patrimonio cultural por parte del IAPH enlaza con la necesidad de innovación en cuanto a los destinatarios y formatos de la formación que venimos realizando en los últimos años. En concreto, se trata de:

> abrir la formación en el IAPH a nuevos destinatarios no profesionales, de forma gratuita y masiva a través de Internet, como servicio público;

> contar con la multidisciplinariedad del personal técnico que trabaja en el IAPH para presentar un relato unitario y didáctico sobre qué es el patrimonio y las actividades que se realizan en torno a su conocimiento, protección conservación y difusión;

> aprovechar la experiencia del IAPH en formación, con más de 20 años organizando actividades formativas en línea, y con un personal experimentado y habituado a este formato, lo que nos facilita institucionalmente abordar este proyecto con garantías.

El MOOC Patrimonio cultural de Andalucía consta de cinco módulos y en su elaboración ha participado un total de 30 profesionales del patrimonio, en su mayoría personal del IAPH, especializados en los diversos contenidos académicos, lo que garantiza su enfoque multidisciplinar. Se han realizado 40 vídeos didácticos, de 

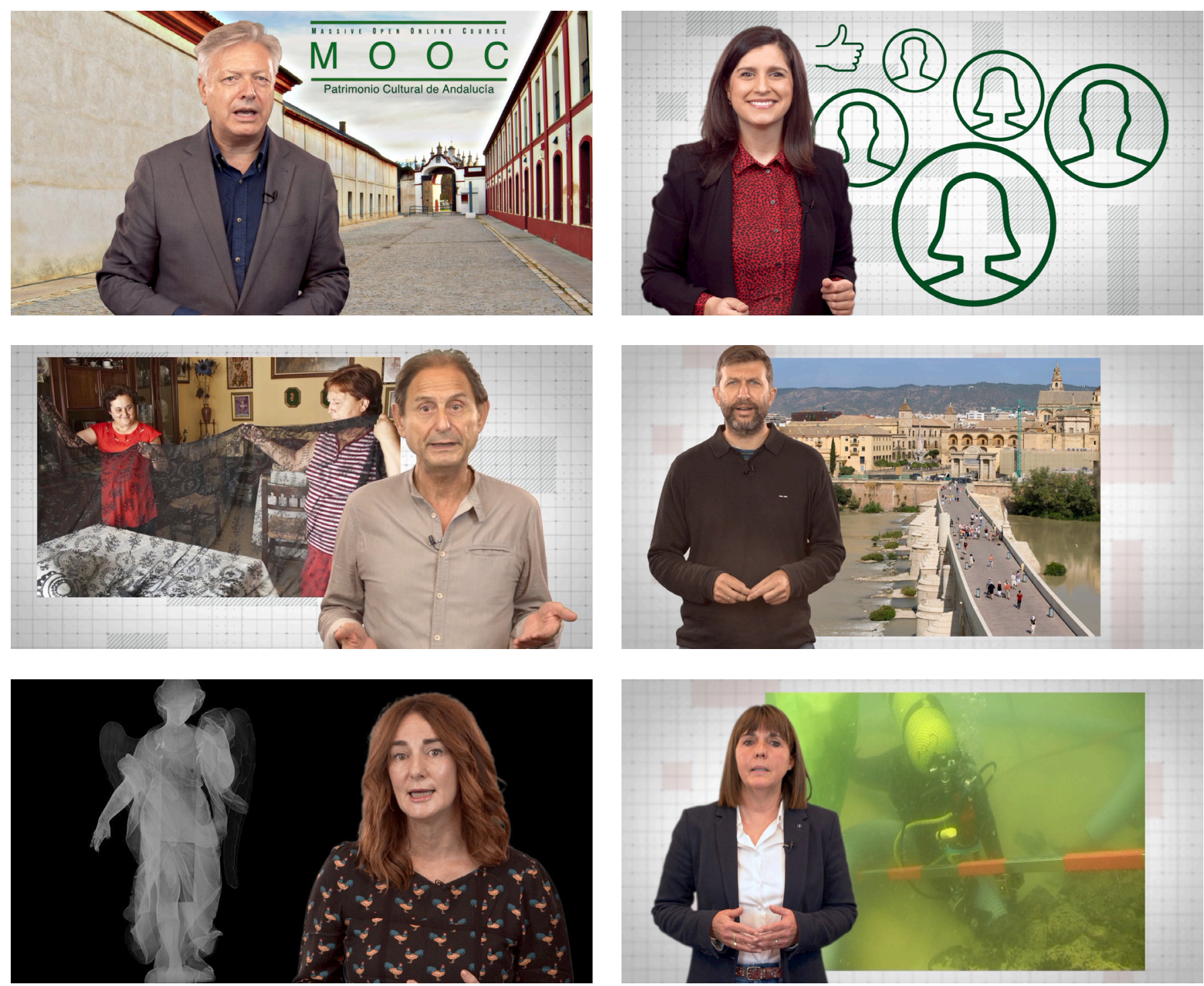

entre 3 y 5 minutos de duración, presentados mayoritariamente por dichos profesionales. Asimismo se ha facilitado al alumnado por cada módulo un texto de lectura complementaria al contenido de los vídeos con bibliografía y otros recursos de información. Cada módulo ha contado con foros de participación y debate moderados por los responsables académicos y un cuestionario de evaluación final.

La primera edición del MOOC se celebró entre el 28 de abril y el 2 de junio de 2021 y se matricularon un total

de 1.337 personas. Al alumnado que ha finalizado con aprovechamiento el MOOC, es decir, un total de 764 personas, se le ha certificado 20 horas de formación en patrimonio cultural de Andalucía. La valoración final del MOOC por parte de las personas participantes ha sido de 6,35 sobre 7 . 

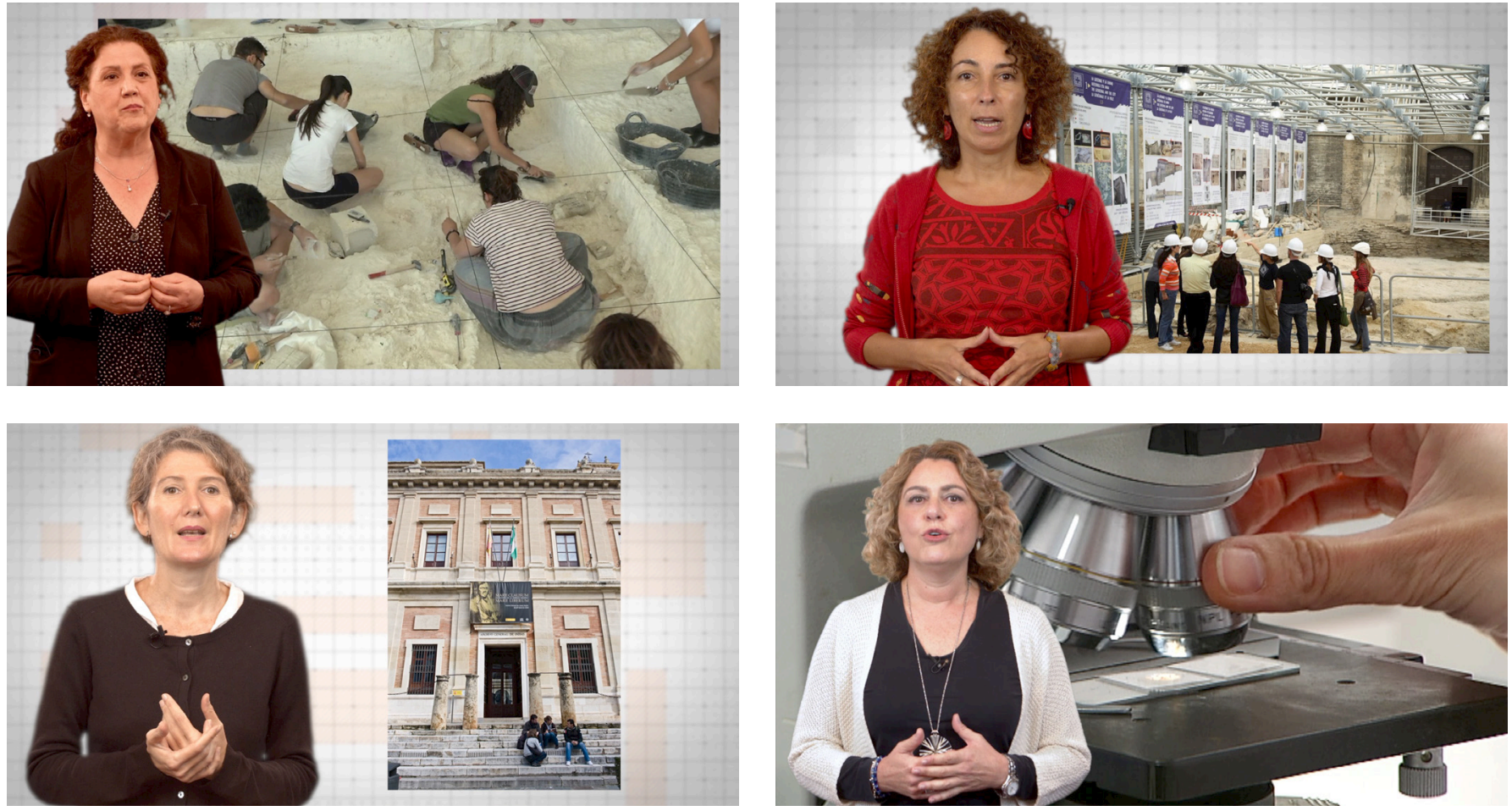

Fotogramas de los vídeos realizados para el MOOC Patrimonio cultural de Andalucía por Alfredo Penella Delgado en 2021

\section{CONTENIDOS DEL MOOC PATRIMONIO CULTURAL DE ANDALUCÍA \\ Módulo I}

¿Qué es el patrimonio cultural?. Orígenes del concepto y su evolución; El patrimonio y la democratización de la cultura; Ampliación del concepto de patrimonio y de los principios para la acción; El patrimonio como recurso para el desarrollo; Multitud de patrimonio/multitud de agentes.

\section{Módulo II}

Presentación del patrimonio cultural de Andalucía. Patrimonio inmueble; Patrimonio mueble; Patrimonio arqueológico;

Patrimonio arqueológico subacuático; Paleobiología; Patrimonio etnológico; Patrimonio inmaterial; Patrimonio industrial; Patrimonio documental y bibliográfico; El paisaje cultural; Guía digital del Patrimonio Cultural de Andalucía.

\section{Módulo III}

Salvaguarda del patrimonio cultural. Investigación y conocimiento; Documentación; Instrumentos de protección; Conservación y restauración; Patrimonio y ciencia; Proyecto de conservación; Difusión.

\section{Módulo IV}

Organismos y competencias en patrimonio cultural. Estado y descentralización; La Consejería de Cultura y Patrimonio Histórico de la Junta de Andalucía; Instituto Andaluz del Patrimonio Histórico; Delitos contra el patrimonio: Fuerzas y cuerpos al servicio de la tutela; La Unión Europea y los organismos internacionales; Patrimonio mundial e inmaterial en Andalucía.

\section{Módulo V}

Patrimonio cultural y sociedad. Construcción social del patrimonio; Acceso y disfrute; Patrimonio y sostenibilidad; Turismo patrimonial; El patrimonio en los medios de comunicación y redes sociales; La importancia de la sensibilización; La formación y las profesiones del patrimonio cultural.

Más info:

https://www.juntadeandalucia.es/

institutodeadministracionpublica/mooc/ 